\title{
The Phenomenal Alleviation of Transmission Congestion by Optimally Placed Multiple Distributed Generators Using PSO
}

\author{
Karuppasamy Muthulakshmi1, Rajamanickam Manickaraj Sasiraja ${ }^{2}$, Velu Suresh Kumar ${ }^{3}$ \\ ${ }^{1}$ Department of Electrical and Electronics Engineering, Kamaraj College of Engineering and Technology, \\ Virudhunagar, India \\ ${ }^{2}$ Department of Electrical and Electronics Engineering, Anna University Regional Campus Madurai, Madurai, \\ India \\ ${ }^{3}$ Department of Electrical and Electronics Engineering, Thiagarajar College of Engineering, Madurai, India \\ Email: muthusashi@gmail.com, rmseee@autmdu.ac.in, vskeee@tce.edu
}

Received 1 April 2016; accepted 1 May 2016; published 16 June 2016

Copyright @ 2016 by authors and Scientific Research Publishing Inc.

This work is licensed under the Creative Commons Attribution International License (CC BY).

http://creativecommons.org/licenses/by/4.0/

(c) (1) Open Access

\section{Abstract}

In the current electricity paradigm, the rapid elevation of demands in industrial sector and the process of restructuring are the main causes for the overuse of transmission systems. Hence, the evolution of novel technology is the ultimate need to avoid the damages in the available transmission systems. An appreciable volume of renewable energy sources is used to produce electric power, after the implementation of deregulation in power system. Even though, they are intended to improve the reliability of power system, the unpredictable outages of generators or transmission lines, an impulsive increase in demand and the sudden failures of vital equipment cause transmission congestion in one or some transmission lines. Generation rescheduling and load shedding can be used to alleviate congestion, but some cases require quite few improved methods. With the extensive application of Distributed Generation (DG), congestion management is also performed by the optimal placement of DGs. Therefore, this research employs a Line Flow Sensitivity Factor (LFSF) and Particle Swarm Optimization (PSO) for the determination of optimal location and size of multiple DG units, respectively. This proposed problem is formulated to minimize the total system losses and real power flow performance index. This approach is experimented in modified IEEE-30 bus test system. The results of $\mathrm{N}-1$ contingency analysis with DG units prove the competence of this proposed approach, since the total numbers of congested lines get reduced from 15 to 2 . Hence, the results show that the proposed approach is robust and simple in alleviating transmission congestion by the optimal placement and sizing of multiple DG units. 


\title{
Keywords
}

\author{
Congestion Management, Line Flow Sensitivity Factor, Distributed Generation, Particle Swarm \\ Optimization
}

\section{Introduction}

Transmission line congestion is one among the major key issues in deregulated power industry. Congestion occurs, when one or more constraints of the system get violated. These violations of restrictions can either be beyond the thermal or voltage limits or some indicated limits. In deregulated power systems, congestion can also occur due to commercial reasons and it has become a major concern. Fast, transparent and effective tools are necessary for congestion management. A comprehensive survey of congestion management methods based on their models is categorized and it is reported [1]. If transmission congestion is relieved, the system returns to its secure state. Mainly, two types of techniques are used to relieve congestion namely, cost free methods and non-cost free methods. The cost free methods includes outage of congested lines, operation and inclusion of transformer taps/phase shifters and placing Distributed Generation (DG) and Flexible AC Transmission Systems (FACTS) devices in distribution and transmission network, respectively. The non-cost free methods are carrying out re-dispatching of active power generation in generators and load curtailment options are coming under this case. An optimal reactive power support from generators and capacitors along with active power rescheduling is reported to manage congestion [2]. The reactive power adjustment is obtained by assuming there is only one system operator. However, in case of several system operators, the management of congestion is complex. A simple direct method is presented for performing generation rescheduling and load shedding to manage transmission congestion [3].

A congestion management method ensuring the voltage security is proposed for congestion management [4]. However, it does not take care about each load. Particle Swarm Optimization (PSO) is used to minimize the rescheduling cost of active power [5]. However, the effect of reactive power of generators and voltage stability constraints are ignored. PSO is used to determine the optimal generation levels to alleviate transmission congestion [6]. Even though this approach claims for its simplicity, the line connecting slack generator does not fully get relieved from congestion. The recent advancements have proven to cater the need of power system by incorporating the benefits of FACTS. The main reason for adding FACTS controllers is to regulate the power flows, transmission voltages and for mitigating the active disturbances [7]. FACTS devices are considered to be one technology that can benefit transmission systems in many ways including congestion management. Many authors have developed various methodologies to incorporate FACTS devices to manage the transmission congestion [8]. The effectiveness of FACTS devices in congestion management depends importantly on their locations. A method is suggested to determine the optimal location of Thyristor Controlled Series Compensator (TCSC) for the reduction of total VAR power losses [9]. Although, this method has good performance to locate TCSC, they may not capture the nonlinearity associated with the system. A new methodology is proposed based on Locational Marginal Pricing (LMP) differences for the location of series FACTS devices for congestion management [10].

A congestion management strategy is proposed for combined operation of hydro and thermal generation companies [11]. However, it computationally demands more efforts and also less reliable. A method is proposed for managing the transmission congestion in a deregulated environment by the combined action of demand response and FACTS devices [12]. But, FACTS devices are modeled in steady state mode and dynamic studies regarding the effects of FACTS devices are not considered. A method is proposed for congestion management in the presence of FACTS devices with Sen Transformer considering load ability limits [13]. However, the authors have experimented only with constant P and Q load models without considering realistic load model. In the recent years, restructuring of electricity market evolves some major improvements in energy production and it increases the usage of distributed generation with renewable energy resources. The introduction of DG units breaks almost all the barriers in the earlier conventional paradigm of electricity generation, transmission and consumption. The definition for DG is given as a tiny power generator and normally distributed within the distribution network [14]. Installing DG units in distribution network result some positive impact as, improvement 
of voltage profile, power quality and reduction in total system loss. Hence, the finding of optimal location and capacity of DG units is important. The possibilities and impacts of DGs are investigated on congestion management [15].

An analytical approach is developed to address the optimal DG placement problem in distribution networks with different topologies [16]. The candidate bus is selected based on the elements of admittance matrix, power generations, and load distribution of distribution network. The issue of DG optimal size is not addressed in this formulation. A simple, but conventional iterative search technique is combined with Newton-Raphson load-flow for finding the optimal placement of DG [17]-[19]. The objective used is to find the optimal location of DG, without considering the DG size. A procedure is proposed to find the optimal location and size of DG simultaneously, but it is limited only for network systems [20]. A sensitivity based method is proposed to allocate DGs simultaneously for congestion relief and voltage security [21].

\section{Proposed Work}

Even though, the major conventional methods are listed in the above chapter as introduction and literature survey, this kind of approach is presented in only one literature [21]. But, in that literature the genetic algorithm is used with the objectives of reducing system losses and maintaining the voltage profile and without considering the performance index value of most severe contingency case. Hence, it is identified that there is a research opening in alleviating transmission congestion with the help of DGs by considering the real power flow performance index for severe contingencies. Therefore, this work utilizes LFSF for the determination of optimal site for the DG units in modified IEEE 30 bus test system.

This organization of this paper is given as follows. In chapter 2, the problem formulation, calculation of Performance Index (PI), contingency selection and optimal location of DGs are elaborated. A brief description about PSO is given in chapter 3 . In chapter 4, the detailed simulation results and discussions are presented. Chapter 5 illustrates some of the conclusions of this work.

\section{Problem Formulation}

Allotment of DGs in order to relieve congestion using N-1 contingency measure certainly leaves some vital solutions against system security danger. A suitable location is identified for the allocation of DG, which could offer an enhanced performance almost in all the circumstances. The process of contingency ranking is performed by using the limits of voltages and power flow performance indices.

\subsection{Contingency Selection}

It is very obvious that various limit violations occur in power system frequently. But, for maintaining the system security, the most severe violations are monitored and evaluated promptly. The magnitude and impact of severity of these vigorous problems should be precisely assessed for enforcing the appropriate corrective measures in order to alleviate this danger. This process of assessment is known as contingency selection. Therefore, contingency analysis is performed in order to evaluate the impact of severe contingencies and to alert the system operator to take a necessary step against this critical contingencies. The violations in transmission line thermal limit, transformer capacity and poor voltages at system buses are listed as common limit violations. The common formula for real power flow performance index is given as Equation (1).

$$
\begin{gathered}
{[P I]^{i}=\sum_{\text {All congested }}\left(\frac{w_{l}}{2 n}\right)\left(\frac{P_{\text {flow low l les }}^{i}}{P_{\max }^{i}}\right)^{2 n}+\sum_{j=1}^{N}\left(\frac{w_{j}}{2 n}\right)\left(\frac{\Delta V_{j}^{i}}{\Delta V_{j}^{\lim }}\right)^{2 n}} \\
\Delta V_{j}^{(i)}=V_{j}^{(i)}-V_{j}^{\lim } \\
V_{j}^{\lim }=V_{j}^{\max }, \forall V_{j}^{(i)} \geq 1.0 \\
V_{j}^{\lim }=V_{j}^{\min }, \forall V_{j}^{(i)}<1.0 \\
V_{j}^{(i)}=V_{j}^{\max }, \forall V_{j}^{(i)}>V_{\max }
\end{gathered}
$$




$$
\begin{gathered}
V_{j}^{(i)}=V_{j}^{\min }, \forall V_{j}^{(i)}<V_{\min } \\
\Delta V_{j}^{\lim }=\frac{V_{j}^{\max }-V_{j}^{\min }}{2}
\end{gathered}
$$

Since a variety of sound failures occurs during the operating period of power system and it creates a contingency group, which possibly guides to congestion or limit violations on some parameters. The normal state of power system can easily be recovered, if these dangerous contingencies are promptly acknowledged with comprehensive assessment and adaptation of appropriate corrective actions. The contingency selection is a way of categorizing significant contingencies and they are ranked based on the real power flow performance index values.

\subsection{Finding the Optimal Locations for DGs Using Line Flow Sensitivity Factor}

The sensitivity on the congested line with respect to power flow is different for all buses in the system. A Line Flow Sensitivity Factor (LFSF) with respect to active and reactive power is calculated for the overloaded lines by considering the change in power flow in a transmission line " $k$ ", connected between the buses " $i$ " and " $j$ ". It can be written as,

$$
\Delta S_{i j}=\frac{\partial S_{i j}}{\partial P_{l}} \Delta P_{l}+\frac{\partial S_{i j}}{\partial Q_{l}} \Delta Q_{l}
$$

Equation (8) can be rewritten as,

$$
\Delta S_{i j}=\frac{\partial S_{i j}}{\partial P_{l}} \Delta P_{l}
$$

By neglecting P-V coupling, Equation (9) can be written as,

$$
\begin{gathered}
{[L F S F]^{l_{o}}=\left(\frac{\partial\left|S_{i j}\right|}{\partial \delta_{i}}\right)\left(\frac{\partial \delta_{i}}{\partial P_{l}}\right)+\left(\frac{\partial\left|S_{i j}\right|}{\partial \delta_{j}}\right)\left(\frac{\partial \delta_{j}}{\partial P_{l}}\right)} \\
T_{i j}=V_{i j}^{4} Y_{i j}^{2}+V_{i}^{2} V_{j}^{2} Y_{i j}^{2}-2 V_{i j}^{3} V_{j} Y_{i j}^{2} \cos \delta_{i j}+2 V_{i}^{3} V_{j} Y_{i j} B_{s h} \sin \left(\theta_{i j}+\delta_{i j}\right) \\
-2 V_{i}^{4} Y_{i j} B_{s h} \sin \theta_{i j}+V_{i}^{4} B_{s h}^{2} \\
\frac{\partial\left|S_{i j}\right|}{\partial \delta_{i}}=T_{i j}^{1 / 2} *\left(V_{i}^{3} V_{j} Y_{i j} \sin \theta_{i j}+V_{i}^{3} V_{j} Y_{i j} B_{s h}\right) \\
\frac{\partial\left|S_{i j}\right|}{\partial \delta_{j}}=-\frac{\partial\left|S_{i j}\right|}{\partial \delta_{i}}
\end{gathered}
$$

Then, this research effort has calculated the values of LFSFs for all the load buses for all contingencies of the most critical outage with the help of above equations. The calculated LFSF values are ranked. The load buses, which have larger negative LFSF values, are selected for DGs allocation, since they are the most influential on the congested line. Hence, this proposed sensitivity factor is fairly fast enough in calculating all the values of LFSFs. Now, the optimal location for the placement of DG unit is achieved. Hence, the effort is now focused towards the computation of optimal size of DG at these selected locations.

\subsection{Computation of the Optimal Size of DGs}

The optimal sizes of the DGs are determined from PSO. The objectives used in this PSO based optimization technique are to determine the optimal size of the DG units by minimizing the real power losses and the real power performance index. The objective function is defined as, 


$$
\text { Min } f=W_{1} \sum_{j} P_{L j}+W_{2} \sum_{\substack{\text { All congested } \\ \text { branches }}} P I
$$

Subjected to,

The voltage magnitude and angle must be kept within standard limits at each bus

$$
\begin{aligned}
& V_{i}^{\min } \leq V_{i} \leq V_{i}^{\max } \\
& \delta_{i}^{\min } \leq \delta_{i} \leq \delta_{i}^{\max }
\end{aligned}
$$

Thermal limit of transmission lines for the network must not be exceeded

$$
\left|S_{i j}\right| \leq\left|S_{i j}^{\max }\right|
$$

\section{Particle Swarm Optimization}

Particle Swarm Optimization is one of the famous stochastic optimization techniques based on population and it is developed by Kennedy and Eberhart [22]. This method is derived from the simulation of a simplified social model of swarms such as fish schooling and bird flocking. PSO is used in solving complex problems that are nonlinear and non-differentiable in nature. It also gives better solutions with multiple optima and high dimensionality through adaptation and thus provides high quality solutions with stable convergence. Whereas genetic algorithms discard the weakest chromosomes immediately, but PSO keeps on over time and influences the search space. PSO has proved in yielding promising results in generation rescheduling for congestion management [5] [6].

\subsection{Steps to Find Solution Using PSO Algorithm}

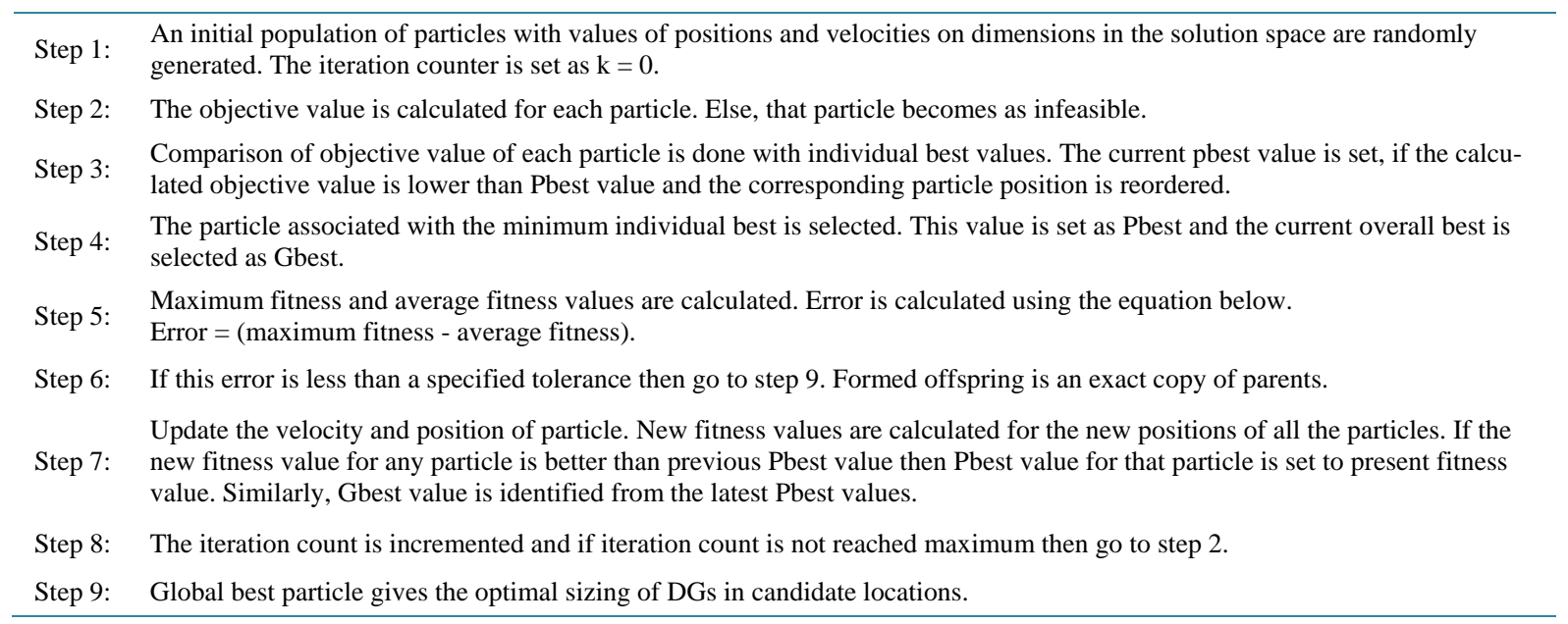

The locations and capacities of multiple DGs are determined by LFSF and PSO algorithm, respectively. The procedural steps involved in this research, which are listed in above steps, are illustrated in flowchart and is given in Figure 1.

\subsection{Parameter Selection for PSO}

The performance of PSO greatly depends on three parameters such as, cognitive parameter $\left(\mathrm{C}_{1}\right)$ and social parameter $\left(\mathrm{C}_{2}\right)$ and weight factors $\mathrm{W}_{\min }$ and $\mathrm{W}_{\max }$. The balance among these factors determines the balance between local and global searching capability. The fitness framed in this research is addition of two components namely summation of total real power losses of the system and summation of real power performance index values of limit violated cases. These two objectives used in this optimization are considered with appropriate weights. The weight value assumed for first objective i.e. minimization of real power losses is 100 and for second objective i.e. minimization of real power performance index is 10 . Hence, the proposed problem with different particle sizes is solved using PSO. The selected parameters are tabulated in Table 1. 


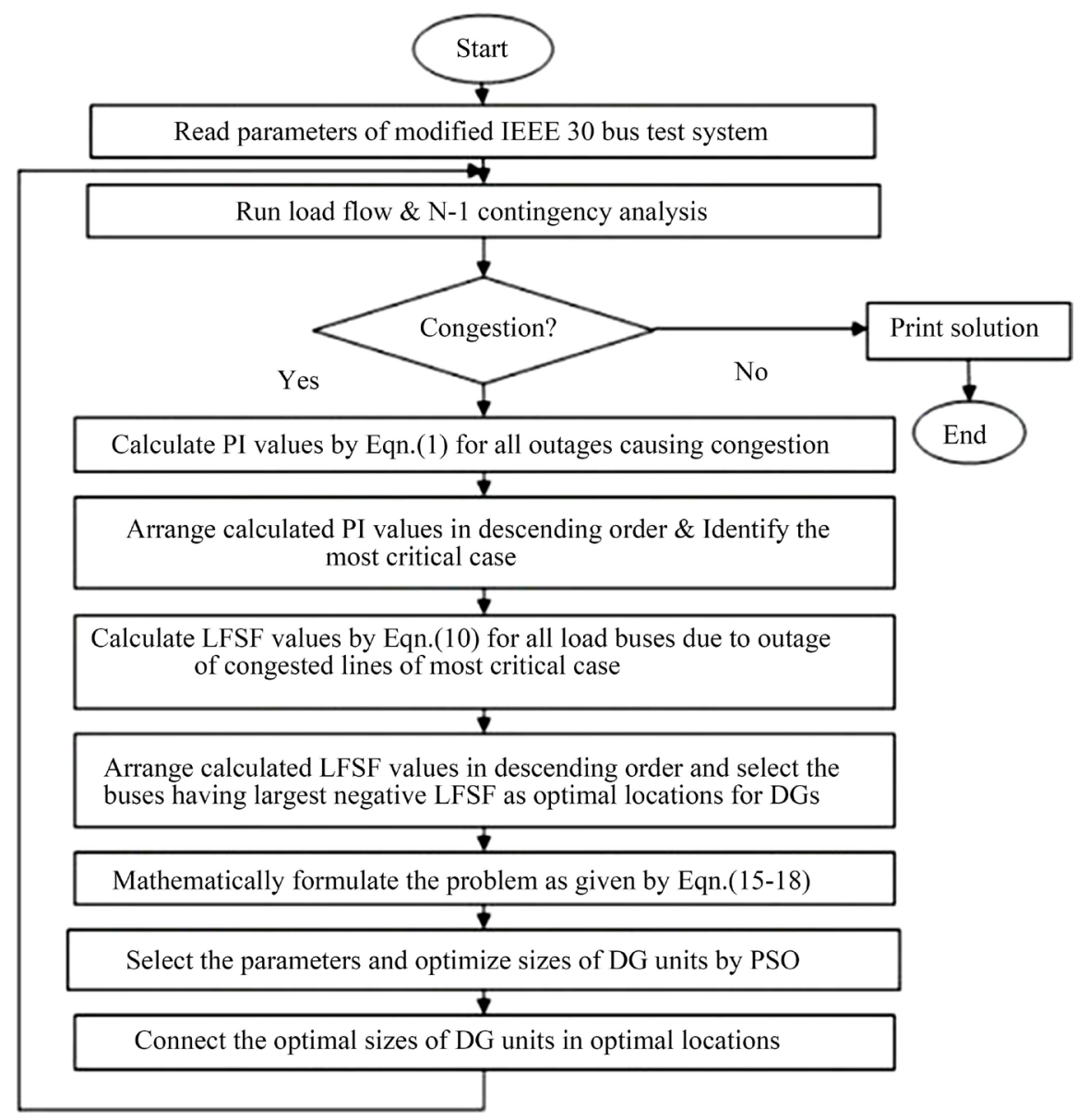

Figure 1. Flowchart of the proposed work.

Table 1. The parameters selection for PSO.

\begin{tabular}{ccccccc}
$\begin{array}{c}\text { Social Factor } \\
\mathrm{C}_{1}\end{array}$ & $\begin{array}{c}\text { Cognitive Factor } \\
\mathrm{C}_{2}\end{array}$ & $\begin{array}{c}\text { Minimum Inertia } \\
\text { Weight Factor } \mathrm{W}_{\min }\end{array}$ & $\begin{array}{c}\text { Maximum Inertia } \\
\text { Weight Factor } \mathrm{W}_{\max }\end{array}$ & $\begin{array}{c}\text { Number of } \\
\text { Particles }\end{array}$ & $\begin{array}{c}\text { Weight for first } \\
\text { objective } \mathrm{W}_{1}\end{array}$ & $\begin{array}{c}\text { Weight for second } \\
\text { objective } \mathrm{W}_{2}\end{array}$ \\
\hline 2 & 2 & 0.4 & 0.9 & 40 & 100 \\
\hline
\end{tabular}

\section{Results and Discussion}

The simulation tests are carried out in modified IEEE 30 bus system to prove the robustness of this proposed ideology. Figure 2 represents the single line diagram of IEEE 30 bus system, which normally consists of 6 generators, 24 load buses and 41 branches [23]. The necessary codes are developed in MATLAB release 2011a with Intel i5 processor equipped with 4 GB RAM.

Initially, Newton Raphson load flow analysis is performed to determine whether the transmission line limit is violated or not. If there is a limit violation, it indicates line congestion. From the results of base case load flow analysis in modified IEEE 30 bus system, it is found that there is no congestion in all the transmission lines. Subsequently, $\mathrm{N}-1$ contingency analysis is performed in order to find out the critical outage cases and the results are presented in Table 2. From Table 2, it is identified that the outage of lines such as 1 - 2, 1 - 3, 3 - 4, 2 - 5, 4 6, 10 - 20 and the outage of generators 2, 5, 8 have caused overloads on some other lines. In this experimentation all the line and generator outage cases, which are listed above, are considered.

The PI values are computed as defined by Equation (1) for all the generators and line outage cases in order to prepare the critical contingency ranking in the system. All the calculated PI values are arranged in descending order and the top nine most critical outage cases along with their PI values are presented in Table 3. From Table 3, it can be found that the outage of line $1-2$ holds the top position and it is known as the most critical contingency in 
this test system. By taking the most critical case (i.e. outage of line 1 - 2), the subsequent calculations are proceeded further.

The congested lines due to outage of most critical case are $1-3,3-4$ and $4-6$ with $48.10 \%, 39.01 \%$ and $25.37 \%$ violation, respectively. The usual practice used to relieve this transmission congestion is performing

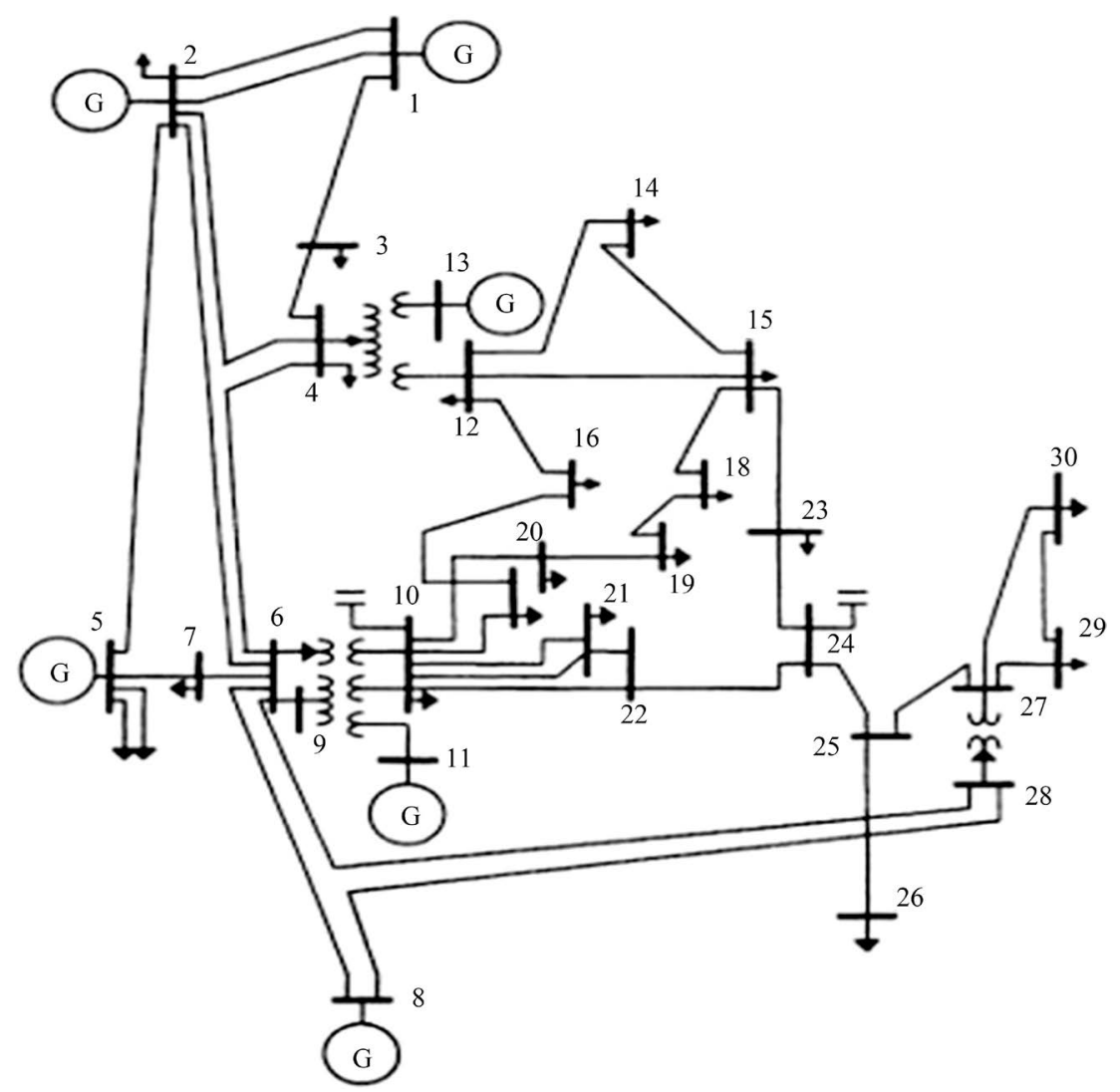

Figure 2. Single line diagram of IEEE 30 bus system.

Table 2. Results of contingency analysis before DG placement.

\begin{tabular}{|c|c|c|c|c|c|}
\hline Sl. No. & Outage of line/Generator & Congested lines & Limit (MVA) & Line flow (MVA) & \% Violation \\
\hline \multirow{3}{*}{1} & \multirow{3}{*}{$1-2$} & $1-3$ & 130 & 192.53 & 48.10 \\
\hline & & $3-4$ & 130 & 180.71 & 39.01 \\
\hline & & $4-6$ & 90 & 112.83 & 25.37 \\
\hline \multirow{2}{*}{2} & \multirow{2}{*}{$1-3$} & $1-2$ & 130 & 182.38 & 40.29 \\
\hline & & $2-6$ & 65 & 66.74 & 2.68 \\
\hline \multirow{2}{*}{3} & \multirow{2}{*}{$3-4$} & $1-2$ & 130 & 178.63 & 37.41 \\
\hline & & $2-6$ & 65 & 65.81 & 1.25 \\
\hline \multirow{2}{*}{4} & \multirow{2}{*}{$2-5$} & $2-6$ & 65 & 76.90 & 18.31 \\
\hline & & $5-7$ & 70 & 75.79 & 8.27 \\
\hline \multirow{2}{*}{5} & \multirow{2}{*}{$4-6$} & $1-2$ & 130 & 134.06 & 3.12 \\
\hline & & $2-6$ & 65 & 71.73 & 10.35 \\
\hline 6 & $10-20$ & $15-18$ & 16 & 16.31 & 1.94 \\
\hline 7 & 2 & $1-2$ & 130 & 162.01 & 24.62 \\
\hline 8 & 5 & $1-2$ & 130 & 136.74 & 5.18 \\
\hline 9 & 8 & $1-2$ & 130 & 135.31 & 4.08 \\
\hline
\end{tabular}


Table 3. Contingency ranking based on PI.

\begin{tabular}{cccc}
\hline Sl. No. & Outage of line/Generator & Total number of congested lines & PI \\
\hline 1 & $1-2$ & 3 & 11.169 \\
2 & $2-5$ & 2 & 5.077 \\
3 & $1-3$ & 2 & 4.843 \\
4 & $3-4$ & 2 & 4.7 \\
5 & $4-6$ & 2 & 4.438 \\
6 & 2 & 1 & 3.042 \\
7 & 5 & 1 & 2.168 \\
8 & 8 & 1 & 2.123 \\
9 & $10-20$ & 1 & 1.040 \\
\hline
\end{tabular}

Table 4. Five possible locations of DG based on LFSF.

\begin{tabular}{|c|c|c|c|c|c|c|}
\hline \multirow{2}{*}{ Sl. No. } & \multicolumn{2}{|c|}{ Line 1 - 3} & \multicolumn{2}{|c|}{ Line 3 - 4} & \multicolumn{2}{|c|}{ Line 4 - 6} \\
\hline & Bus No. & LFSF & Bus No. & LFSF & Bus No. & LFSF \\
\hline 1 & 22 & -0.3698 & 22 & -0.1817 & 23 & -0.3965 \\
\hline 2 & 23 & -0.3120 & 23 & -0.1486 & 22 & -0.3689 \\
\hline 3 & 9 & -0.3052 & 7 & -0.1185 & 29 & -0.2428 \\
\hline 4 & 7 & -0.2746 & 15 & -0.1035 & 19 & -0.2393 \\
\hline 5 & 3 & -0.2720 & 21 & -0.0918 & 21 & -0.2392 \\
\hline
\end{tabular}

Table 5. Optimal capacity of DGs using PSO.

\begin{tabular}{ccc}
\hline Sl. No. & Bus No. & Optimal DG capacity in MW using PSO \\
\hline 1 & 22 & 36.7206 \\
2 & 23 & 17.7379 \\
\hline
\end{tabular}

rescheduling of generators. But in this work, the DGs are placed at the suitable locations of the load buses as corrective action for relieving congestion. To find the suitable location of DGs, LFSF (explained in Section 3.2) values are calculated for each of the overloaded lines for the most critical contingency and the top five preferred locations for each of the overloaded lines are given in Table 4. Among these five values, the bus which has most negative LFSF value is selected as the optimal location for placing DG. Because, the bus, which has the highest negative value, is the most sensitive and responsive for the placement of DG units. Here, the objective of this research is to reduce or eliminate the level of congestion by finding the optimal location and size of DG units.

It can be observed that buses 22 and 23 have the highest negative values and they are selected as most suitable locations for the placement of DGs with respect to the overloaded lines 1 - 3, 3 - 4 and 4 - 6, respectively. Then, the optimal sizes of DGs are determined from PSO algorithm and the results are presented in Table 5.

From Table 5, the optimal DG capacity at the buses 22 and 23 are 36.7206 MW and 17.7379 MW, respectively. The fitness characteristics against iteration are shown in Figure 3. The fitness is continuously decreasing in nature but at the same time, all the considered constraints are getting satisfied.

It is worthy to note that the total numbers of congested lines during various contingency cases get reduced from 15 to 2 by the placement of the DG units at their suitable locations. The congested lines due to N-1 contingency cases are almost alleviated by the optimal placement of multiple DG units except line 5 - 7 and 15 - 18 due to outage of line 2 - 5 and 10 - 20, respectively. Even though the congestion in these lines is not completely eliminated, the level of congestion in these lines is getting reduced from $8.27 \%$ and $1.94 \%$ to $7.77 \%$ and $1.81 \%$ for outage of line 2 - 5 and 10 - 20, respectively. The results of contingency analysis without and with the DG units are presented in Table 6. Hence, congestion relief by optimal DG placement with the help of PSO algorithm is good enough to provide the anticipated results.

The comparison of results, with and without the multiple DG units are summarized and presented in Table 7. 


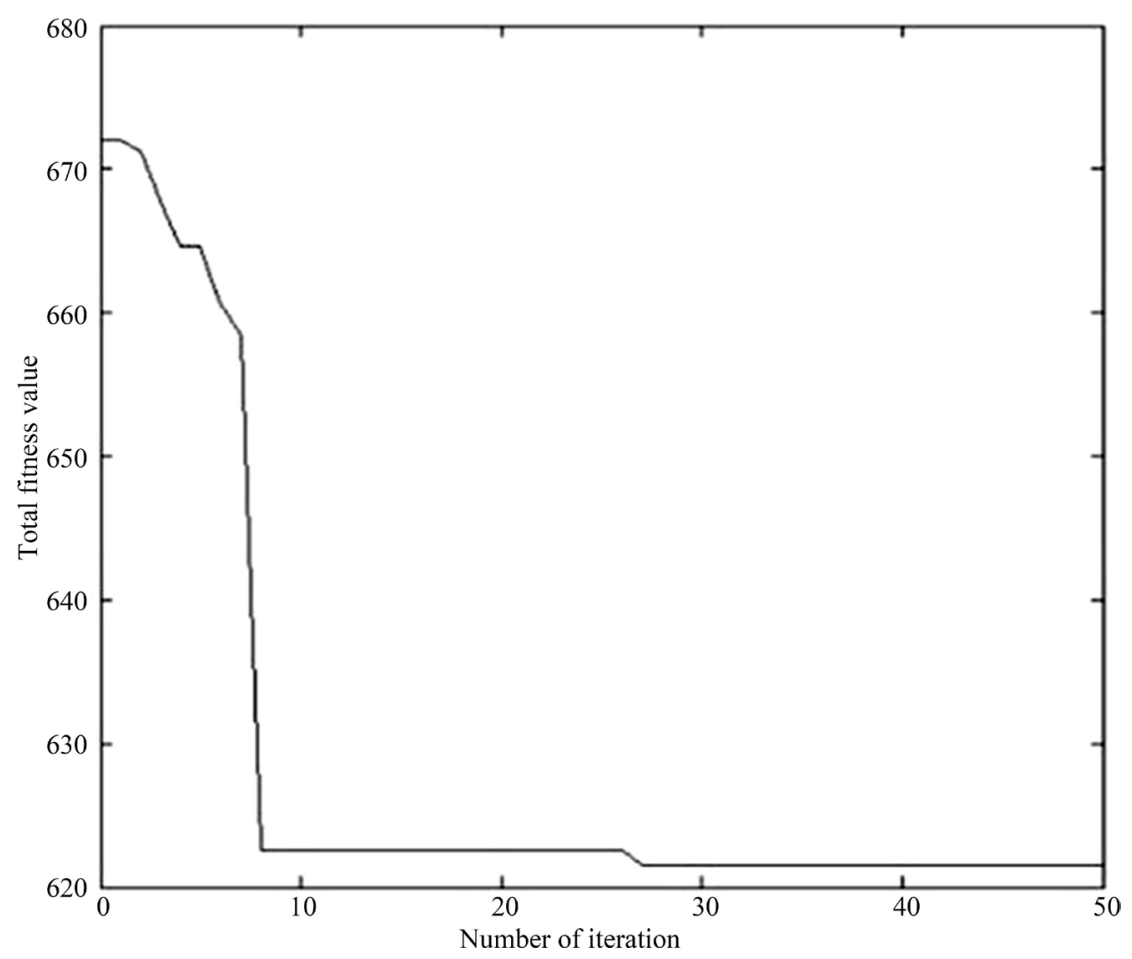

Figure 3. Fitness curve obtained using PSO.

Table 6. Comparison of contingency analysis before and after DG placement.

\begin{tabular}{|c|c|c|c|c|c|c|}
\hline $\begin{array}{l}\text { Sl. } \\
\text { No. }\end{array}$ & $\begin{array}{c}\text { Outage of } \\
\text { line/Generator }\end{array}$ & $\begin{array}{l}\text { Congested } \\
\text { lines }\end{array}$ & $\begin{array}{l}\text { Limit } \\
\text { (MVA) }\end{array}$ & $\begin{array}{l}\text { Line flow without DG units } \\
\text { (MVA) }\end{array}$ & $\begin{array}{l}\text { Line flow with DG units } \\
\text { (MVA) }\end{array}$ & $\%$ Violation \\
\hline \multirow{3}{*}{1} & \multirow{3}{*}{$1-2$} & $1-3$ & 130 & 192.53 & 125.36 & Alleviated \\
\hline & & $3-4$ & 130 & 180.71 & 118.73 & Alleviated \\
\hline & & $4-6$ & 90 & 112.83 & 75.39 & Alleviated \\
\hline \multirow{2}{*}{2} & \multirow{2}{*}{$1-3$} & $1-2$ & 130 & 182.38 & 120.69 & Alleviated \\
\hline & & $2-6$ & 65 & 66.74 & 42.61 & Alleviated \\
\hline \multirow{2}{*}{3} & \multirow{2}{*}{$3-4$} & $1-2$ & 130 & 178.63 & 118.05 & Alleviated \\
\hline & & $2-6$ & 65 & 65.81 & 41.72 & Alleviated \\
\hline \multirow{2}{*}{4} & \multirow{2}{*}{$2-5$} & $2-6$ & 65 & 76.90 & 56.54 & Alleviated \\
\hline & & $5-7$ & 70 & 75.79 & 75.44 & 7.77 \\
\hline \multirow{2}{*}{5} & \multirow{2}{*}{$4-6$} & $1-2$ & 130 & 134.06 & 90.86 & Alleviated \\
\hline & & $2-6$ & 65 & 71.73 & 46.05 & Alleviated \\
\hline 6 & $10-20$ & $15-18$ & 16 & 16.31 & 16.29 & 1.81 \\
\hline 7 & 2 & $1-2$ & 130 & 162.01 & 122.993 & Alleviated \\
\hline 8 & 5 & $1-2$ & 130 & 136.74 & 98.129 & Alleviated \\
\hline 9 & 8 & $1-2$ & 130 & 135.31 & 96.525 & Alleviated \\
\hline
\end{tabular}

Table 7. Comparison of results before and after placing DGs.

\begin{tabular}{|c|c|c|c|c|}
\hline Cases Factors & $\begin{array}{c}\text { Before DG } \\
\text { placement }\end{array}$ & $\begin{array}{c}\text { After DG placement } \\
\text { using PSO }\end{array}$ & Reduction & \% Reduction \\
\hline Base case $\mathrm{P}_{\text {loss }}(\mathrm{MW})$ & 9.482 & 5.914 & 3.568 & 37.63 \\
\hline Base case $\mathrm{Q}_{\text {loss }}(\mathrm{MVAR})$ & -9.897 & -26.354 & 16.457 & 166.28 \\
\hline Total Number of congested lines during various contingencies & 15 & 2 & 13 & 86.66 \\
\hline PI value for the outage of line 2 - 5 & 5.077 & 2.389 & 2.688 & 52.94 \\
\hline PI value for the outage of line $10-20$ & 1.040 & 1.037 & 0.003 & 0.29 \\
\hline
\end{tabular}


The placement of DG units in identified optimal locations results a notable reductions in real, reactive power losses and total number of congested lines with a percentage of $37.63 \%, 166.28 \%, 86.66 \%$, respectively. The real power performance index values for outage of line 2 - 5 and line $10-20$ get reduced with a percentage of $52.94 \%$ and $0.29 \%$, respectively.

The reduction in real power losses after DG placement is shown in Figure 4. It is also inferred that PSO provides better reduction in real power losses and real power performance index. It is evident that PSO achieves an effective performance for the factors considered i.e., real power loss and real power performance index.

To validate the sturdiness of this proposed approach in reaching the optimal or near optimal solution, 25 independent and continuous runs are performed with the same level of maximum iteration, i.e., 50 iterations with two different particle sizes i.e. 20 and 40. The results are compared with the statistical investigation and they are given in Table 8. It is clear from Table 8 that the simulation using 40 particles is the most preferred one, because the value of standard deviation is comparatively less. Normally, the standard deviation is the parameter, which is chosen for the analysis ruggedness of any optimization algorithm. Hence, the standard deviation is calculated here also for analyzing the competency of this proposed method.

The comparative plot between total fitness value and number of run with 20 and 40 particles is shown in Figure 5. The maximum and minimum values of 25 independent runs with 20 and 40 particles can be easily noted down from Figure 5. The fitness value with 40 particles is comparatively less among these two values. Hence, the best fitness value with 40 particles iteration has the best performance characteristics.

\section{Conclusion}

Congestion in transmission network is effectively relieved by the optimal placement and sizing of multiple DG units. It is obvious that inappropriate size and incorrect location of DG units induce higher power losses and

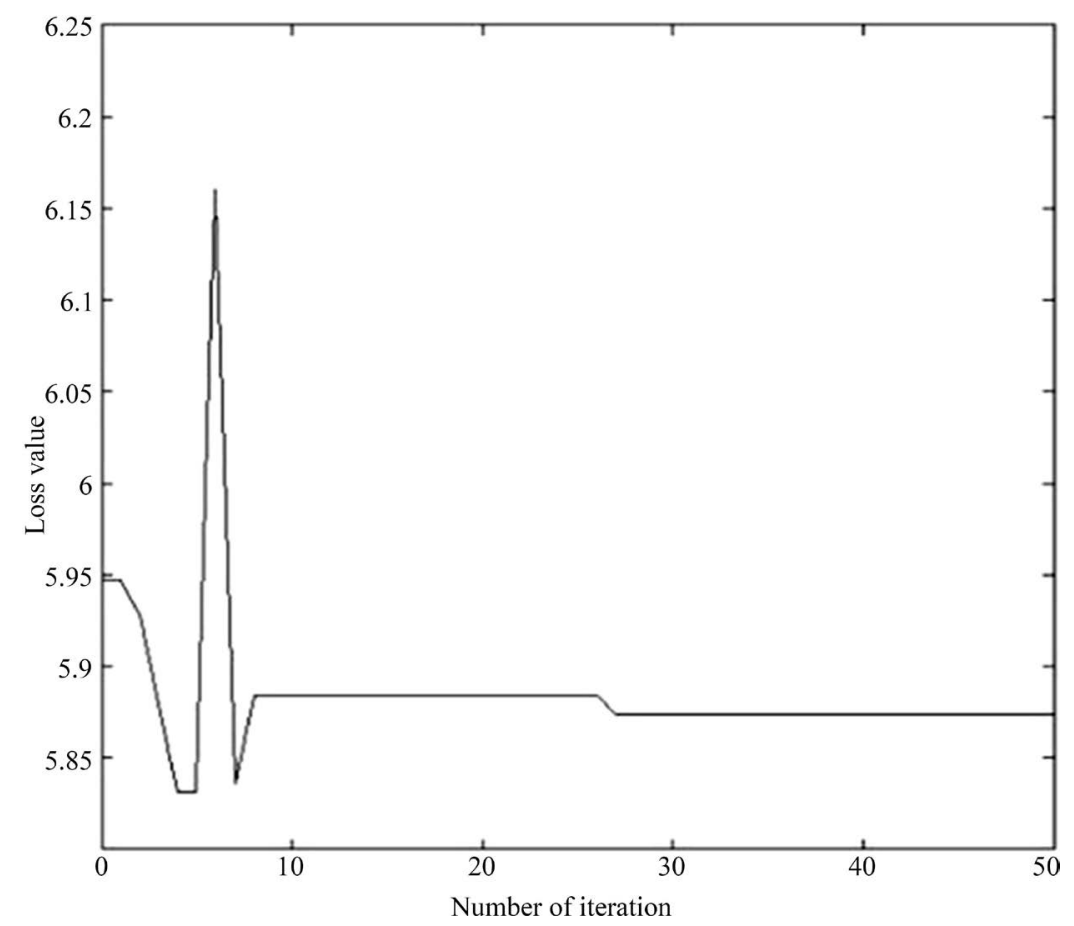

Figure 4. Convergence characteristics of real power losses using PSO.

Table 8. Statistical analysis with 25 independent runs.

\begin{tabular}{cccccc}
\hline \multirow{2}{*}{ Sl. No. } & \multirow{2}{*}{ Number of Particles } & \multicolumn{4}{c}{ Total Fitness Value } \\
\cline { 3 - 6 } & & Best & Worst & Mean & Standard Deviation \\
\hline 1 & 20 & 621.5341 & 661.8594 & 632.7218 & 11.8301 \\
2 & 40 & 621.1392 & 660.0684 & 627.7925 & 10.2189 \\
\hline
\end{tabular}




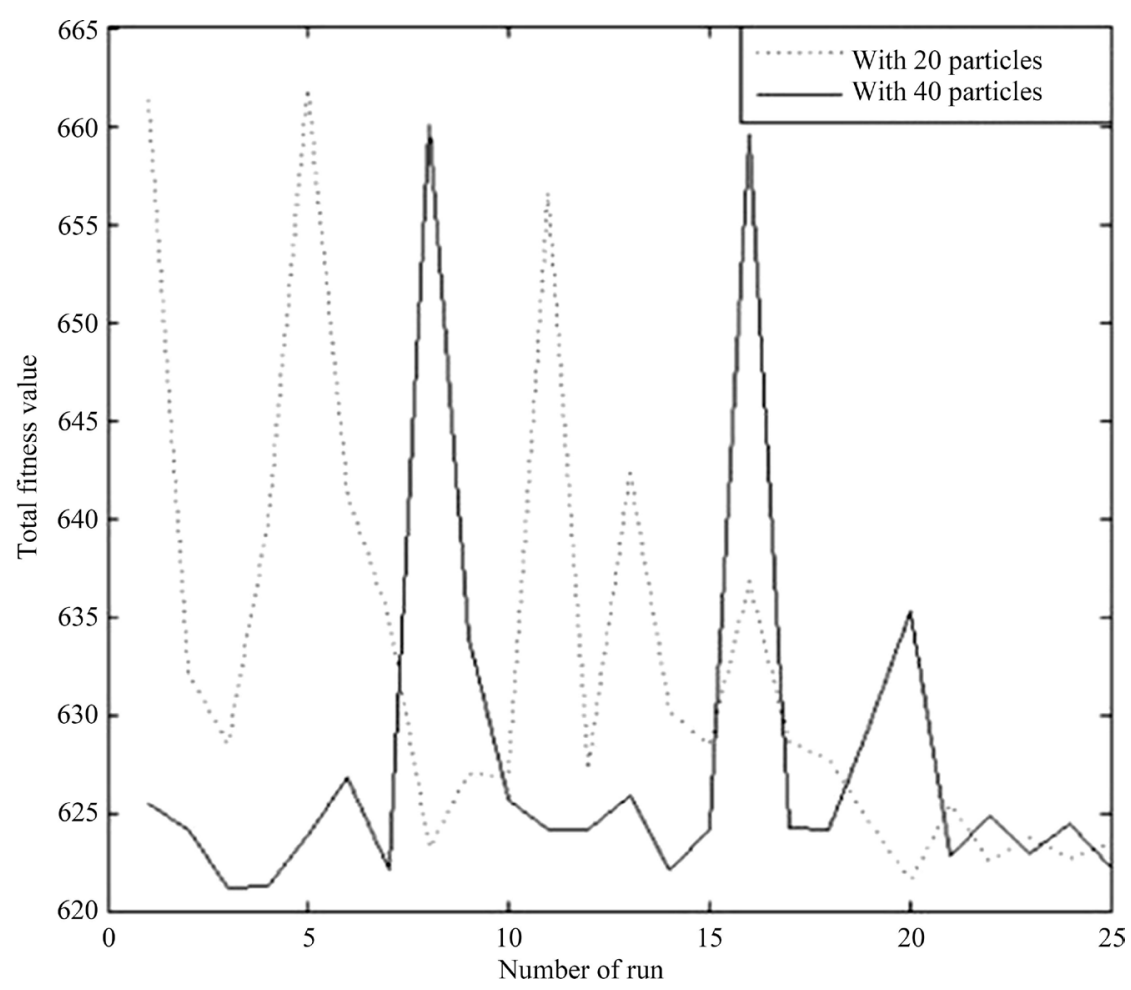

Figure 5. Plot with different particle size.

horrible voltage troubles. Therefore, this research employs LFSF to determine the most favorable sites of DG units and PSO for choosing the best size of DGs. The objective of this investigation is minimization of real power losses and real power performance index. The pragmatism of the projected method is tested in modified IEEE 30 bus test system. The results of N-1 contingency analysis with DGs prove the competence of this proposed approach, since the total numbers of congested lines get reduced from 15 to 2 . Even though, this approach claims for its simplicity, still there are 2 congested lines for some critical cases. To overcome this bottleneck, modern approaches like demand side management and FACTS devices may be added additionally along with this proposed method to relieve the congestion completely. This method of congestion relief by PSO demonstrates competent, sturdy and straightforward, since it has considered the minimization of performance index as objective. In order to prove the usefulness of this proposed approach, statistical study is also carried out and the results are given. Comparatively, this method of relieving congestion is superior, since it employs renewable energy sources, which help for the reduction of environmental pollution.

\section{Acknowledgements}

The authors of this manuscript express their heartfelt gratitude to the Management of Kamaraj College of Engineering \& Technology, Thiagarajar College of Engineering and the authorities of Anna University Regional Campus Madurai for aiding the essential amenities to complete this research.

\section{References}

[1] Kumar, A., Srivastava, S.C. and Singh, S.N. (2005) Congestion Management in Competitive Power Market: A Bibliographical Survey. Electric Power Systems Research, 76, 153-164. http://dx.doi.org/10.1016/j.epsr.2005.05.001

[2] Kumar, A., Srivastava, S.C. and Singh, S.N. (2004) A Zonal Congestion Management Approach Using Real and Reactive Power Rescheduling. IEEE Transactions on Power Systems, 19, 554-562.

[3] Talukdar, B.K., Sinhaa, A.K., Mukhopadhyay, S. and Bose, A. (2005) A Computationally Simple Method for CostEfficient Generation Rescheduling and Load Shedding for Congestion Management. International Journal of Electric Power \& Energy Systems, 27, 379-388.

[4] Conejo, A. J., Milano, F. and García-Bertrand, R. (2006) Congestion Management Ensuring Voltage Stability. IEEE 
Transactions on Power Systems, 21, 357-364. http://dx.doi.org/10.1109/TPWRS.2005.860910

[5] Dutta, S. and Singh, S.P. (2008) Optimal Rescheduling of Generators for Congestion Management Based on Particle Swarm Optimization. IEEE Transactions on Power Systems, 23, 1560-1568. http://dx.doi.org/10.1109/TPWRS.2008.922647

[6] Muthulakshmi, K. and Babulal, C.K. (2014) Relieving Transmission Congestion by Optimal Rescheduling of Generators Using PSO. Applied Mechanics and Materials, 626, 213-218. www.scientific.net/AMM.626.213

[7] Hingorani, N.G. and Gyugyi, L. (2000) Understanding FACTS. Concepts and Technology of Flexible AC Transmission Systems. IEEE Press, New York.

[8] Brosda, J. and Handschin, E. (2001) Congestion Management Methods with Special Consideration of FACTS Devices. IEEE International Conference on Power Techniques, Vol. 1, Porto, 10-13 September 2001. http://dx.doi.org/10.1109/PTC.2001.964593

[9] Besharat, H. and Taher, S.A. (2008) Congestion Management by Determining Optimal Location of TCSC in Deregulated Power Systems. International Journal of Electric Power \& Energy Systems, 30, 563-568. http://dx.doi.org/10.1016/j.ijepes.2008.08.007

[10] Acharya, N. and Mithulananthan, N. (2007) Locating Series FACTS Devices for Congestion Management in Deregulated Electricity Markets. Electric Power Systems Research, 77, 352-360. http://dx.doi.org/10.1016/j.epsr.2006.03.016

[11] Singh, K., Padhy N.P. and Sharma, J. (2011) Congestion Management Considering Hydro-Thermal Combined Operation in a Pool Based Electricity Market. International Journal of Electric Power \& Energy Systems, 33, 1513-1519. http://dx.doi.org/10.1016/j.ijepes.2011.06.037

[12] Yousefi, A., Nguyen, T.T., Zareipour, H. and Malik, O.P. (2012) Congestion Management Using Demand Response and FACTS Devices. International Journal of Electric Power \& Energy Systems, 37, 78-85. http://dx.doi.org/10.1016/j.ijepes.2011.12.008

[13] Kumar, A. and Sekhar, C. (2013) Congestion Management with FACTS Devices in Deregulated Electricity Markets Ensuring Loadability Limit. International Journal of Electric Power \& Energy Systems, 46, 258-273. http://dx.doi.org/10.1016/j.ijepes.2012.10.010

[14] El-Khattam, W. and Salama, M.M.A. (2004) Distributed Generation Technologies, Definitions and Benefits. Electric Power Systems Research, 71, 119-128. http://dx.doi.org/10.1016/j.epsr.2004.01.006

[15] Liu, J., Salama, M. and Mansour, R. (2005) Identify the Impact of Distributed Resources on Congestion Management. IEEE Transactions on Power Delivery, 20, 1998-2005.

[16] Acharya, N., Mahat, P. and Mithulananthan, N. (2006) An Analytical Approach for DG Allocation in Primary Distribution Network. International Journal of Electric Power \& Energy Systems, 28, 669-678. http://dx.doi.org/10.1016/j.ijepes.2006.02.013

[17] Gautam, D. and Mithulananthan, N. (2007) Optimal DG Placement in Deregulated Electricity Market. Electric Power Systems Research, 77, 1627-1636. http://dx.doi.org/10.1016/j.epsr.2006.11.014

[18] Wang, C.S. and Nehrir, M.H. (2004) Analytical Approaches for Optimal Placement of Distributed Generation Sources in Power Systems. IEEE Transactions on Power Systems, 19, 2068-2076. http://dx.doi.org/10.1109/TPWRS.2004.836189

[19] Keane, A. and Malley, M.O. (2005) Optimal Allocation of Embedded Generation on Distribution Networks. IEEE Transactions on Power Systems, 20, 1640-1646. http://dx.doi.org/10.1109/TPWRS.2005.852115

[20] Ghosh, S., Ghoshal, S.P. and Ghosh, S. (2010) Optimal Sizing and Placement of Distributed Generation in a Network System. International Journal of Electric Power \& Energy Systems, 32, 849-856. http://dx.doi.org/10.1016/j.ijepes.2010.01.029

[21] Singh, A.K. and Parida, S.K. (2013) Congestion Management with Distributed Generation and Its Impact on Electricity Market. International Journal of Electric Power \& Energy Systems, 48, 39-47. http://dx.doi.org/10.1016/j.ijepes.2012.11.025

[22] Kennedy, J. and Eberhart, R. (1995) Particle Swarm Optimization. IEEE International Conference on Neural Networks, Perth, Nov/Dec 1995, 1942-1948.

[23] Zimmerman, R.D., Murillo-Sánchez, C.E. and Thomas, R.J. (2011) MATPOWER: Steady-State Operations, Planning, and Analysis Tools for Power Systems Research and Education. IEEE Transactions on Power Systems, 26, 12-19. http://dx.doi.org/10.1109/TPWRS.2010.2051168 


\section{Submit or recommend next manuscript to SCIRP and we will provide best service for you:}

Accepting pre-submission inquiries through Email, Facebook, Linkedin, Twitter, etc A wide selection of journals (inclusive of 9 subjects, more than 200 journals)

Providing a 24-hour high-quality service

User-friendly online submission system

Fair and swift peer-review system

Efficient typesetting and proofreading procedure

Display of the result of downloads and visits, as well as the number of cited articles

Maximum dissemination of your research work

Submit your manuscript at: http://papersubmission.scirp.org/ 